\title{
Comparison of the nutrient content of different types of lunchtime meal, and their contribution towards the overall daily nutrient intakes of 11 14-year-old schoolchildren from two schools in Scotland
}

\author{
C. L. Norris, H. I. M. Davidson, R. Rush and M. E. Clapham \\ Health Sciences, Queen Margaret University, Musselburgh, Edinburgh EH21 6UU, UK
}

Due to concern regarding the nutritional quality of schoolchildren's diets, large amounts of funding have been invested into improving school canteen lunches. However, children may also consume packed lunches, or 'street' lunches (those purchased outside school). This study was undertaken to ascertain whether canteen lunches are nutritionally superior to packed and street lunches, the contribution of the lunch types towards total nutritional intake, and whether children eating nutritionally poor lunches compensate in terms of nutritional intake and density with food consumed at other times.

During 2007 and 2008, dietary intake data were collected from 332 children aged 11-13, from two schools in Fife, Scotland. Using 5-d estimated intake food diaries, data from $1532 \mathrm{~d}$ was collected. Energy intake was calculated, as well as intake and density (per $100 \mathrm{kcal}=418.4 \mathrm{~kJ}$ ) of fat, SFA, non-milk extrinsic sugars $(\mathrm{NMES})$, non-starch polysaccharides (NSP), vitamin A, folate, Ca, Fe plus fruit/vegetables. These nutrients/foods were selected due to their inclusion in the Scottish Nutrient Standards for School Meals (SNSSL) ${ }^{(1)}$. Lunchtime data were compared with the SNSSL, and the total daily intake with the estimated average requirement for energy $^{(2)}$, dietary reference values (DRV) and reference nutrient intakes (RNI) for nutrients and micronutrients ${ }^{(2)}$ and the government recommendation for fruit and vegetables ${ }^{(3)}$. Comparisons were undertaken between canteen, packed and street lunches and between days including them.

The children's diet was closest to guidelines when canteen lunches were consumed, having the lowest mean fat, SFA and NMES intakes, and the highest mean folate, $\mathrm{Ca}$ and Fe. However, many dietary targets remained unmet. On street lunch days, the diet was furthest from guidelines, with the lowest intake for NSP, micronutrients, and fruit and vegetables. This occurred both at lunchtime and over the whole day. Packed lunches contained the most vitamin A, NSP and fruit/vegetable portions (mean values). They also contained more SFA than canteen or street lunches.

There was some compensation for poor lunchtime nutrient intake by foods eaten at other times during the day. However, this was not as great as noted by previous studies ${ }^{(4-6)}$, and many significant differences between the lunch types existed at the end of the day.

Children should therefore be encouraged to have canteen lunches due to their superior nutritional quality, and their contribution towards overall nutrient intake.

1. Scottish Executive. Nutrition in Schools (2003) Scottish Nutrient Standards for School Lunches. Edinburgh: Scottish Executive.

2. Department of Health (2003) Report on Health and Social Subjects 41. Dietary Reference Values for Food Energy and Nutrients for the United Kingdom. Report of the Panel on Dietary Reference Values of the Comittee on Medical Aspects of Food Policy (12th impression). Report No. 41. Norwich: The Stationery Office.

3. Department of Health (2003). 5-a-day health benefits.

4. Cook J, Altman DG et al. (1975) School meals and the nutrition of schoolchildren. Br J Prev Soc Med 29, 182-189.

5. Department of Health (1989) The Diets of British Schoolchildren. Committee on Medical Aspects of Food Policy, Sub-committee on Nutritional Surveillance, Report on Health and Social Subjects No. 36. London: HM Stationery Office.

6. Durnin JVGA, Lonergan ME et al. (1974) A cross-sectional nutritional and anthropometric study, with an interval of 7 years, on 611 young adolescent schoolchildren. Br J Nutr 32, 169-179. 